\title{
Study on reasonable nozzle size after volumetric fracturing of glutenite reservoir
}

\author{
Shi Le ${ }^{1}$, Li Ruochen ${ }^{1}$, Luo Gan ${ }^{1}$, Gu Li Za Dan•Mao Lahong ${ }^{1}$, Li Bin ${ }^{2}$, Chen Jing ${ }^{2}$, Li Yi ${ }^{2, *}$ \\ ${ }^{1}$ No.2 Production Plant, Xinjiang Oilfield Company, PetroChina, Karamay, Xinjiang, China \\ ${ }^{2}$ Tianjin Zhengfang Science and Technology Development Co., Ltd., Tianjin, China
}

\begin{abstract}
What kind of drainage system should be adopted after the volumetric fracturing of the glutenite reservoir in the Mahu 1 well area, lack of systematic research. The reasonable choice of the size of the nozzle is the key to determining the flow back of the fracturing fluid and stable production. By comparing the applicability differences of fracturing and drainage systems at home and abroad, this paper analyzes the production experience of neighboring areas and determines the overall principles of drainage system: small displacement principle, stable drainage principle and step-by-step amplification principle. Then, by calculating the rate of change of oil production, analyzing the system well test curve and production curve, and determining a reasonable drainage system, it is concluded that the volume of the glutenite reservoir after fracturing should be $1.5 \mathrm{~mm}$ small nozzle, and the pressure is gradually stabilized. The grade is replaced by a $2.5 \mathrm{~mm}$ nozzle. Most of the wells are finally stabilized in the $3.0 \mathrm{~mm}$ nozzle production. A small number of wells can be properly enlarged to a $3.5 \mathrm{~mm}$ nozzle for stable production. Under the guidance of this understanding, the horizontal wells in the Mahu 1 well area have basically reached the design capacity, providing theoretical basis and guidance for the production practice after volume fracturing.
\end{abstract}

\section{Introduction}

The Mahu Oilfield in the Junggar Basin is proved to be an important oil and gas enrichment area. It is dominated by Permian and Triassic glutenite alluvial fans and fan delta-type oil and gas reservoirs ${ }^{[1]}$. Thearea between the Urho Formation in the upper Permian series and the Baikouquan Formation in the lower Triassic series forms a set of coarse-grained near-provenance sediments in the background of depression basins a set of coarse-grained near provenance sedimentation is formed under the background of depression basin ${ }^{[2]}$. They are mainly composed of conglomerate-coarse sandstones, containing a small amount of fine ones. The gravels are mainly the tuff and andesite debris ${ }^{[3]}$. At present, the development of Mahu Lake is in full swing ${ }^{[4]}$, but there is no similar experience for us to directly turn to for reference.

Many experts have conducted detailed research and analysis on relevant flow-back systems for coalbed methane, low permeability sandstone gas reservoirs, and shale gas after fracturing. Zhao established a mathematical model of the size of the flow-back nozzle after posing CBM well pressure to determine a reasonable post-fracturing nozzle system for CBM ${ }^{[5]}$. Zhang et al. believe that in order to prevent the fracturing fluid from causing secondary damage to the water-sensitive reservoir of low-permeability natural gas reservoirs in Xinjiang oilfield, it is necessary to drain back the fracturing fluid in time and establish a matching relationship between the wellhead pressure and the optimal oil nozzle ${ }^{[6]}$. Yin proved through experiments that the flow-back speed is the decisive factor affecting proppant backflow, which is mainly in the initial stage of flow-back. A small nozzle should be used in the initial stage. If there is no sand production, it is feasible to increase the flow-back speed so as to complete the process more quickly ${ }^{[7]}$. Ai believes that proppant backflow is an important factor in evaluating the fracturing effect. Through mechanical analysis of the proppant during the reflow process, the critical conditions can be obtained so as to determine a reasonable flow-back scheme ${ }^{[8]}$. Liu et al. quantitatively studied the effects of different construction displacements, proppant types, and proppant pumping procedures on the law of proppant sedimentation in volume fracturing through experiments and determined a reasonable flow-back system ${ }^{[9]}$. However, there is a lack of systematic research on the production system after the fracturing of glutenite reservoirs. The reasonable selection of the size of the fuel injection nozzle is the key to determining the result of forced flow-back of fracturing fluid ${ }^{[10]}$. Based on the analysis of a large number of on-site mining test data, this paper obtains a reasonable drainage system rule, which can provide theoretical basis and guidance for production practice after volume fracturing in the Mahu Lake area.

\footnotetext{
* Corresponding author: 654549059@qq.com
} 


\section{Principles of production system}

There are two viewpoints on the production system of fractured horizontal wells. The first one refers to the practice of tight oil in foreign countries (mass production in the initial stage; quick investment drawback in the stable and declining stage); the second one means to maximize the role of natural energy by maintaining a certain production volume to achieve smooth production for a longer period of time. Through comparative analysis, the overall production system shall meet the following two principles.

\subsection{Small displacement principle}

Reservoir in Mahu 1 Well is mainly composed of glutenite. For example, according to the analysis data of the thin section of the cast body, the pore types of Baikouquan Formation in the Triassic series in Mahu 1 Well are mainly intragranular dissolved pores, primary intergranular pores, and remaining intergranular pores. According to analysis of 336 reservoir samples, the porosity of the reservoir ranges from $3.21 \%$ to $14.8 \%$, with an average of $8.95 \%$; the permeability ranges from $0.02 \times 10^{-3} \mu \mathrm{m}^{2}$ to $134 \times 10^{-3} \mu \mathrm{m}^{2}$, with an average of $1.83 \times$ $10^{-3} \mu^{2}$ (low-porosity and low-permeability reservoir); the oil saturation ranges from $45 \%$ to $55 \%$ with the characteristics of low-saturation reservoirs. In general, Mahu $1 \mathrm{Well}$ has poor reservoir properties. It has low oil saturation and its type of storage space is not conducive to fluid communication. Therefore, it is not suitable for large-volume production.

Secondly, by comparing the oil production per unit pressure drop using different nozzles in the surrounding area of Mahu Lake (Figure 1), we can see that the oil production per unit pressure drop decreases with the increase of the nozzle size. Although large nozzles can increase fluid production volume, high fluid production volume is obtained at the cost of significant pressure loss. As the pressure decreases, the self-injection capacity of production wells also decreases, which ultimately affects the cumulative oil production.

Finally, large-volume production is likely to cause backflow of proppant, leading to greater sand production [11-12]. Therefore, the glutenite reservoir in Mahu 1 Well is suitable for small-volume production after fracturing.

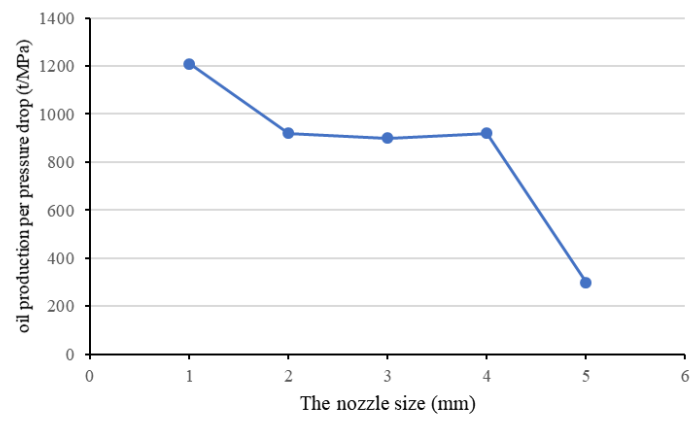

a. $\mathrm{M} * * * * 004$ well

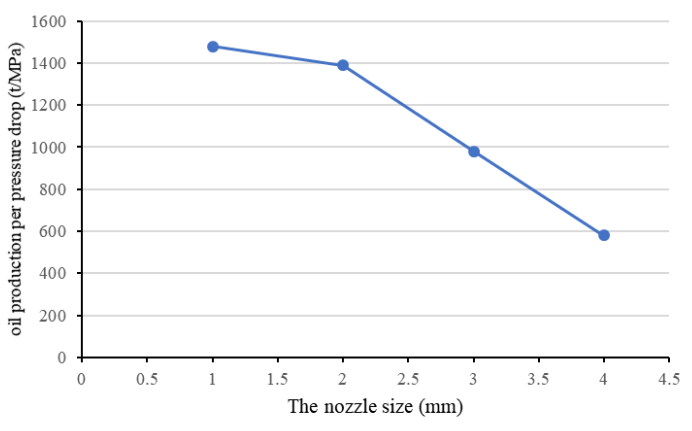

b. $\mathrm{M} * * * 001$ well

Fig. 1. Relationship between the size of the typical well nozzle and the oil production per unit pressure drop surrounding Mahu area

\subsection{Principle of stable drainage}

Due to the lack of similar oil reservoirs for direct reference, the nozzle size is often determined by field engineers. Repeated adjustment of the nozzle will cause pressure instability and large fluctuations in water content (Figure 2), which will further affect the fluid displacement from the matrix to the fracture network, and ultimately influence the cumulative oil production. Therefore, glutenite reservoirs after fracturing shall follow a stable drainage system.

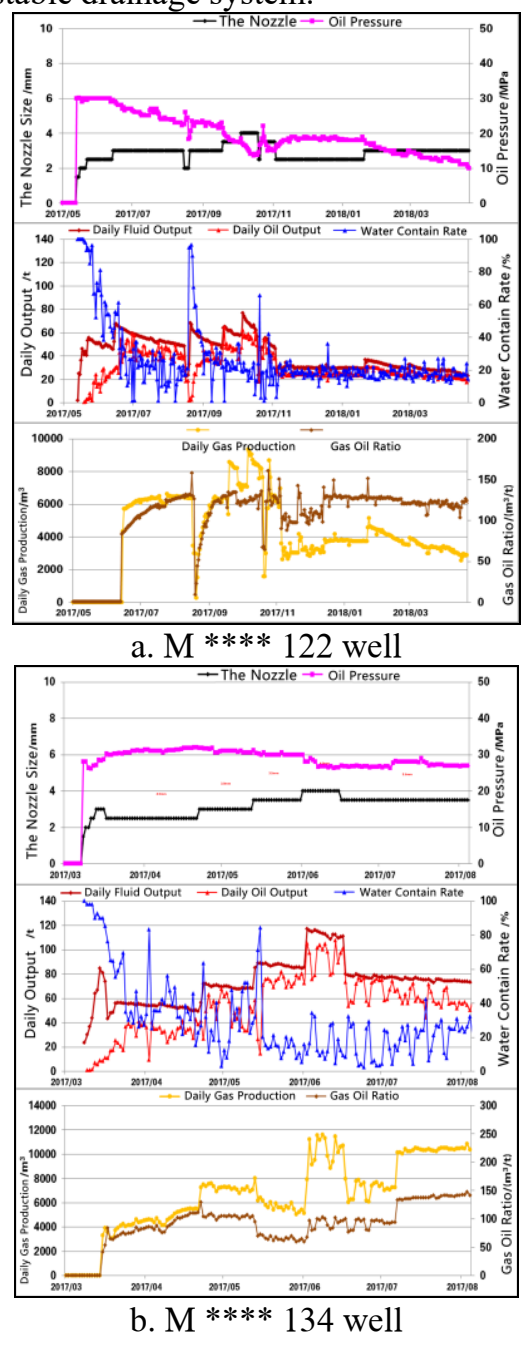

Fig. 2. Typical well production curve 


\subsection{Step-up principle}

$60 \%$ of the work can be completed in the first $30 \%$ of blowdown time. The whole process is fast in the beginning with greater pressure and speed, and then slows down. Therefore, small nozzles can help to control the blowdown speed and the production pressure difference, thereby ensuring the stable distribution of proppant ${ }^{[13-15]}$. In the later stage, as the blowdown slows down, the size of the nozzle increases in response (Figure 3).

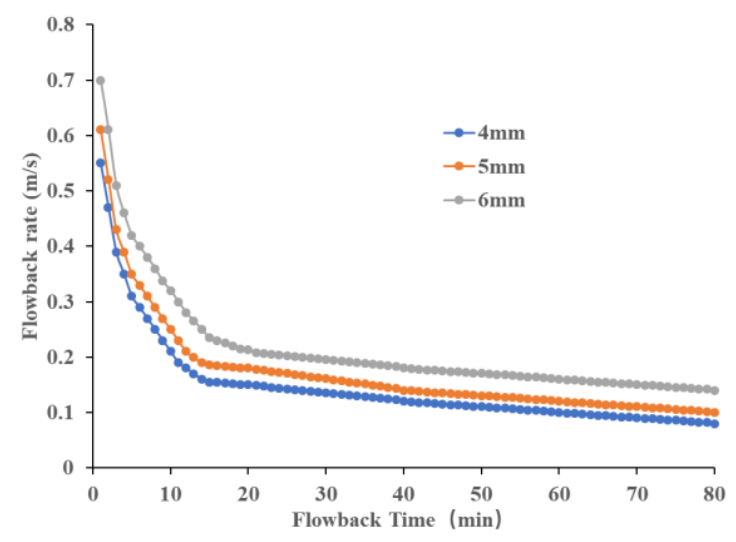

Fig. 3. Curve of return velocity with time under different nozzle radius

\section{Reasonable well opening system}

Before the well is opened, for wells with no or short soak time, the fracture may be unclosed and the proppant may be still in a suspended state. The large nozzle will quickly guide the proppant to the wellbore. Therefore, it is necessary to use small oil nozzles to close the fractures first before blowdown production. For wells with sufficient soak time, although the fractures may have closed naturally, many proppants will settle at the bottom of the fracture. Large oil nozzles tend to cause a large pressure difference, which will change the proppant distribution and may lead to sand production. Therefore, large nozzles shall be used after the well is opened and the pressure is released using a small nozzle. In short, according to the step-up principle, $1.5 \mathrm{~mm}$ nozzles should be used in the initial well opening stage.

\section{Reasonable blowdown system}

The fracture closure process can be divided into two types according to whether the well is soaked before opening. For wells with no or short soak time, the fractures need to be forcibly closed by releasing pressure; for wells with sufficient soak time, the pressure is passed through fractures from the fracture network to the matrix rock layer, which causes the fracture to close naturally.

If the fracture is forcibly closed, proppant particles are concentrated in the fracture near the wellbore side under the traction of the fracturing fluid. Based on the force analysis of a single proppant particle, the major impetus received at the critical starting moment the particle reflux is the tractive force of the fracturing fluid, and the main resistance is the viscous resistance of the fracturing fluid. The fracturing fluid backflow calculation model can be used to calculate the fracture closing time corresponding to different nozzle sizes. The closing time and the critical flow rate of fracturing fluid backflow can be used to select the maximum nozzle size for preventing proppant backflow ${ }^{[16-17]}$.

If the fracture is naturally closed, then the proppant particles settle at the bottom of the fracture [18-20]. According to the discrimination methods of oil production change rate and the method of systematic well test, we can obtain a reasonable nozzle size and determine a reasonable production system.

\subsection{Discrimination method of oil production change rate}

Continuously monitor the oil production and pressure data on daily basis and calculate the oil production rate per daily unit pressure drop using the following formula.

$$
\alpha=\frac{Q}{\Delta P}
$$

In the formula, $\alpha$ refers to the daily oil pressure per unit pressure drop, $\mathrm{t} /(\mathrm{MPa} \cdot \mathrm{d}) ; \mathrm{Q}$ is the daily oil output, $\mathrm{t} / \mathrm{d} ; \Delta$ $\mathrm{P}$ is the daily pressure drop, MPa. By differentiating (1), we can get

$$
\beta=\frac{d Q}{d \Delta P}
$$

$\beta$ is the change rate of oil production per unit pressure drop, $\mathrm{t} /\left(\mathrm{MPa} \cdot \mathrm{d}^{2}\right)$; $\mathrm{dQ}$ is the change of daily oil production, $\mathrm{t} / \mathrm{d} ; \Delta \mathrm{P}$ is the change of daily pressure drop, $\mathrm{MPa}$.

If $\beta=0$, then it is proved that the nozzle size is reasonable; if $\beta>0$, then the nozzle is proved to be slightly smaller, and we should use smaller nozzles.

\subsection{Discrimination method of systematic well test}

Referring to the IPR curve of well tests of the two well systems of the nearby Baikouquan Formation, we can see a turning point at the $3.0 \mathrm{~mm}$ nozzle in the curve of $\mathrm{M}^{* * * * 122}$ well, and the rate of change in fluid production suddenly increases after the turning point, indicating that when the nozzle is too large, the amount of pressure change will exceed that of production fluid change (Figure 4). At the same time, from the oil production indexes corresponding to different oil nozzles, we can see that the oil production index of $\mathrm{M}^{* * * *} 122$ well reaches its peak at $3.0 \mathrm{~mm}$ (Table 1), while the oil production indexes of $\mathrm{M}^{* * * *} 134$ well using $3.0 \mathrm{~mm}$ and $3.5 \mathrm{~mm}$ nozzles show little difference (Table 1), and that the oil production index drops sharply for some well using $3.5 \mathrm{~mm}$ nozzles (Figure 4). Based on a comprehensive analysis, most of the well nozzles reasonable for production are $3.0 \mathrm{~mm}$; based on the result 
of oil production change rate obtained using the discrimination method of oil production rate change, it is feasible to increase the nozzle size to $3.5 \mathrm{~mm}$ for stable production.

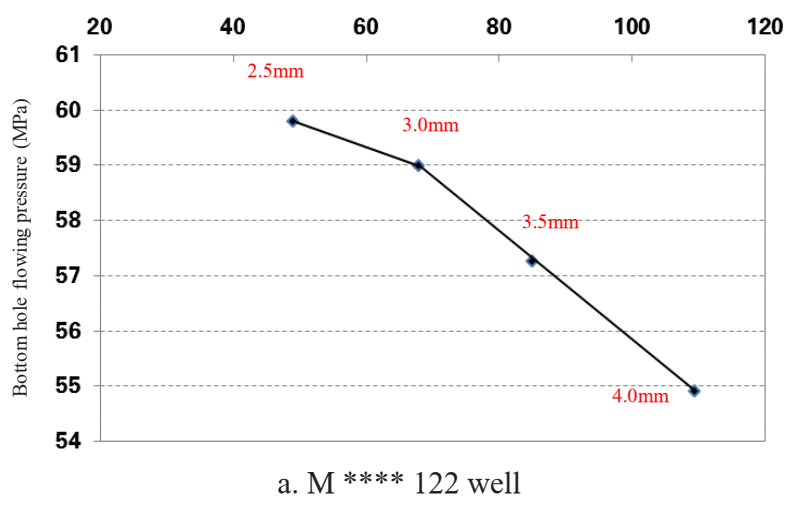

Daily Fluid Output (t/d)

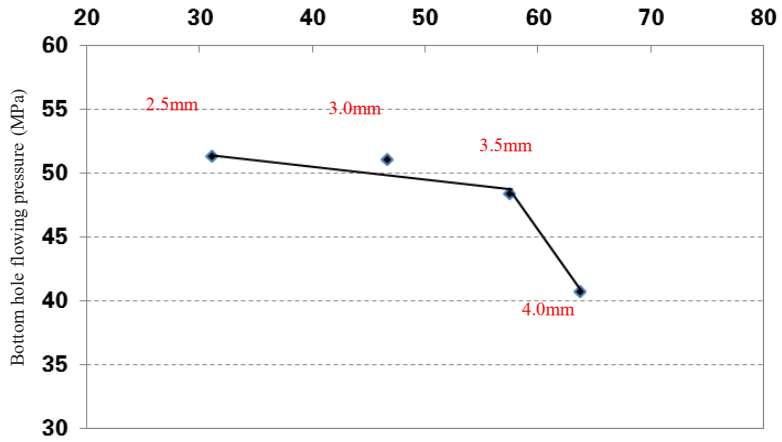

b. $\mathrm{M}^{* * * * 134 \text { well }}$

Fig.4. System well test curve

Table 1. System Well Test Indicator Table

\begin{tabular}{|c|c|c|}
\hline \multirow{2}{*}{$\begin{array}{c}\text { The Nozzle Size } \\
(\mathrm{mm})\end{array}$} & \multicolumn{2}{|c|}{ Productivity Index $(\mathrm{t} / \mathrm{d} \cdot \mathrm{MPa})$} \\
\cline { 2 - 3 } & $\mathrm{M}^{* * * * 122}$ & $\mathrm{M}^{* * * * 134}$ \\
\hline 2.5 & 6.98 & 8.58 \\
\hline 3.0 & 9.19 & 10.24 \\
\hline 3.5 & 6.50 & 10.95 \\
\hline 4.0 & 4.23 & 9.56 \\
\hline
\end{tabular}

\subsection{Empirical discrimination method of production curves}

Based on the production practice of multiple wells, it is proved that once the nozzle size is enlarged to $4.0 \mathrm{~mm}$, the pressure will drop sharply (Figure 5). The final size of nozzles for stable production shall not exceed $4.0 \mathrm{~mm}$.

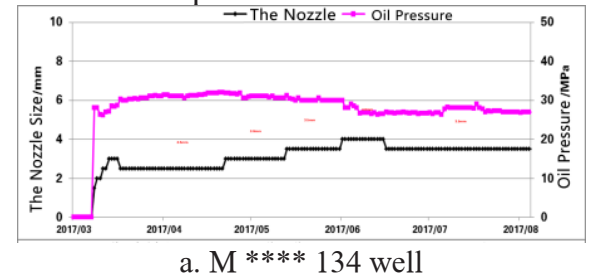

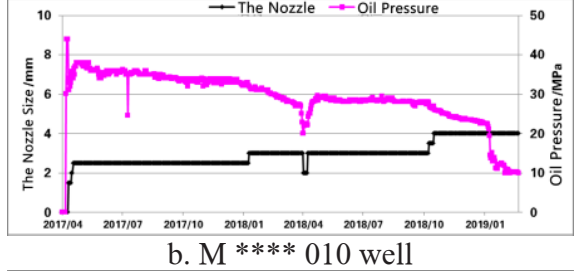
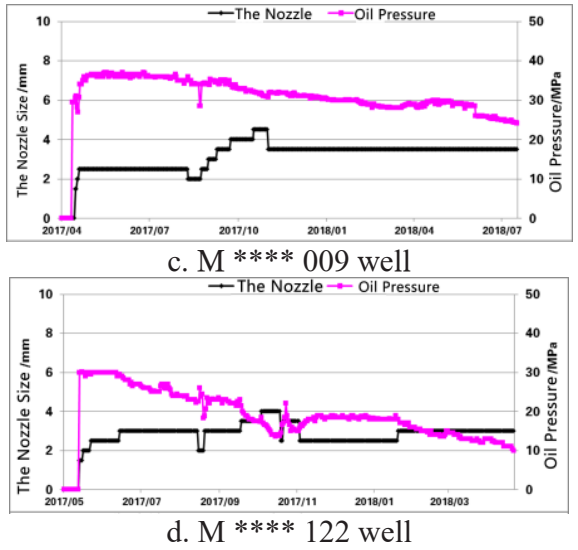

Fig.5. Curve of nozzle size and oil pressure

\section{Mine test verification}

Based on the above analysis, a $1.5 \mathrm{~mm}$ nozzle should be used during well opening; then the $\beta$ value can be calculated using the discrimination method of oil production change rate can based on the data of daily oil production and daily pressure, and $\beta$ value is used to determine whether the size of the nozzle is reasonable. After that, gradually enlarge the nozzle size to $2.5 \mathrm{~mm}$, and most wells adopt $3.0 \mathrm{~mm}$ nozzle, while a some wells can adopt $3.5 \mathrm{~mm}$ nozzles for stable production; the final nozzle size shall not exceed $4.0 \mathrm{~mm}$.

According to the above production system, 5 out of 6 horizontal wells in the two production platforms of the Urho Formation reservoir in Mahu 1 Well reach the designed capacity, and the remaining one is close, with a daily oil production of $12.8 \sim 43.9 \mathrm{t} / \mathrm{d}$ (Table 2 ).

However, the two experimental horizontal wells of Baikouquan Formation reservoir in the Mahu 1 Well area fail to reach the designed production capacity at present due to the earlier production time and the lack of a reasonable production system.

Table 2. Table of production of Upper Urho Formation reservoir in Mahu 1 Well area

\begin{tabular}{|c|c|c|c|c|c|c|}
\hline Well & $\begin{array}{c}\text { Nozzle } \\
\text { Size } \\
(\mathrm{mm})\end{array}$ & $\begin{array}{c}\text { Daily } \\
\text { Fluid } \\
\text { Output } \\
(\mathrm{t})\end{array}$ & $\begin{array}{c}\text { Daily } \\
\text { Oil } \\
\text { Output } \\
(\mathrm{t})\end{array}$ & $\begin{array}{c}\text { Water } \\
\text { Contain } \\
(\%)\end{array}$ & $\begin{array}{c}\text { Casing } \\
\text { Pressure } \\
(\mathrm{MPa})\end{array}$ & $\begin{array}{c}\text { Number } \\
\text { of Days } \\
(\mathrm{d})\end{array}$ \\
\hline $\mathrm{M} 2 * * * 1$ & 3.0 & 50.7 & 43.9 & 13.3 & 6.5 & 146 \\
\hline $\mathrm{M} 2 * * * 2$ & 2.5 & 30.6 & 19.7 & 35.5 & 8.0 & 96 \\
\hline $\mathrm{M} 2 * * * 3$ & 2.5 & 33.2 & 17.9 & 46.1 & 9.3 & 140 \\
\hline $\mathrm{M} 1 * * * 1$ & 2.5 & 52 & 13.3 & 74.5 & 25.9 & 120 \\
\hline $\mathrm{M} 1 * * * 2$ & 3.0 & 69.5 & 22.9 & 67.0 & 29.9 & 96 \\
\hline $\mathrm{M} 1 * * * 3$ & 3.0 & 58.7 & 12.8 & 78.2 & 26.0 & 106 \\
\hline
\end{tabular}




\section{Conclusions}

(1) The production system of glutenite reservoirs after fracturing should follow the principle of small displacement, the principle of stable drainage, and the step-up principle.

(2) The reasonable production system can be determined by applying the discrimination method of oil production change rate, the discrimination method of systematic well test, and the empirical discrimination method of production curves.

(3) After the fracturing of glutenite reservoirs, it is appropriate to use $1.5 \mathrm{~mm}$ nozzles and then change to $2.5 \mathrm{~mm}$ ones after the pressure is gradually stabilized. Most wells will finally adopt $3.0 \mathrm{~mm}$ nozzles, and some will adopt $3.5 \mathrm{~mm}$ ones for stable production. The final size of the nozzle shall not exceed $4.0 \mathrm{~mm}$.

\section{References}

1. HE Dengfa, WU Songtao, ZHAO Long, et al. Sedimentary tectonic setting and evolution of the Permian-Triassic surround the mahu Sag[J]. Xinjiang Petroleum Geology, 2018, 39(01) : 35-47.

2. TANG Yong, XU Yang, LI Yazhe, et al. Sedimentary model and exploration significance of large shallow water retreating fan delta in Mahu sag[J]. Xinjiang Petroleum Geology, 2018, 39(01) : $16-22$.

3. LU Xinchuan, SHI Ji'an, GE Bing, et al. Characteristics of the Upper Wuerhe Formation glutenite reservoir in the Middle-Bearing-Wuba area of the northwestern margin of the Junggar Basin[J]. Lithologic Reservoirs, 2012, 24(06) : 54-59.

4. DU Hongling, XU Jiangwen, LI Wei, et al. Development and deepening of benefit development of tight glutenite reservoirs in Xinjiang oilfieldPractice and reflection on integration of geological engineering in Mahu area[J]. China Petroleum Exploration, 2018, 23(02) : 15-26.

5. ZHAO Qihong. Study on the method for determining the nozzle size after fracturing [D]. Southwest Petroleum University, 2017.

6. ZHANG Feng, CHEN Xiaoming, HONG Jiangling, et al. Study on optimization of backflow system after low permeability reservoir in Xinjiang[J]. Geology and Prospecting, 2019, 55(02) : 622-629.

7. GUO Jianchun, WANG Xingwen, ZHAO Jinzhou, et al. Analysis of pressure drop analysis model considering the compressibility of jet and fracturing fluids[J]. Drilling \& Production Technology, 2004, 27(5) : 24-30.

8. AI Chi, ZHANG Yonghui, ZHAO Wanchun, et al. Study on proppant recirculation in fracturing fluid returning process $[\mathrm{J}]$. Oil Drilling \& Production Technology, 2012, 34(02) : 70-73.

9. LIU Junchen, PENG Huan, GAO Xinping, et al. Experimental study on settlement of volumetric fracturing proppant in seam[J]. Drilling \& Production Technology, 2019, 42(05) : 39-42+8.

10. JIANG Tingxue, YAN Yun, ZHANG Shaoli, et al. Dynamic optimization method for the diameter of the nozzle during the back-discharge after hydraulic fracturing $[\mathrm{J}]$. Petroleum Drilling Techniques, 2008, 36(2) : 55-59.

11. SUN Liangtian, SUN Meixia, LIU Yaoxu, et al. Application of reservoir numerical simulation in fracturing design of Shuanghe Oilfield[J]. Fault Block Oil and Gas Field, 2001, 8(1) : 59-61.

12. JIANG Tingxue, WANG Xugang, GUAN Wenlong, et al. A new model for pressure drop analysis under forced closed conditions of cracks[J]. Journal of Petroleum, 2003, 24(1) : 78-81.

13. ZHANG Shicheng, WANG Hongxun. Numerical calculation of hydraulic fracturing design [M]. Beijing: Petroleum Industry Press, 1998: 48-78.

14. YUAN Wen-yi, XIE Jian-li, YIN Shu-li, et al. Evaluation of the conductivity of mixed proppant induced by slug $[\mathrm{J}]$. Fault Block Oil and Gas Field, 2009, 16(6) : 121-125.

15. LI Tiancai, GUO Jianchun, ZHAO Jinzhou. Research and application of proppant recirculation and sand production control in fracturing gas wells[J]. Journal of Xi'an Shiyou University: Natural Science Edition, 2006, 21(3) : 44-47.

16. CHEN Donglin, ZHANG Baoying, TAN Mingwen, et al. New development of proppant reflow control technology [J]. Natural Gas Industry, 2006, (01) : 101-103+167-168.

17. Zhang Yonghui. Study on proppant recirculation during fracturing fluid returning process [D]. Northeast Petroleum University, 2011.

18. WANG Xiang. Research on the mechanism of fracturing fluid returning and its backflow control during crack closure[D]. Graduate School of Chinese Academy of Sciences (Institute of Fluid Flow Mechanics), 2004.

19. WU Yahong, WEN Qingzhi, ZHANG Lingxiao, et al. Control optimization on proppant spiting [J]. Fault-Block Oil \& Gas Field , 2012, 19 (5) : 662665.

20. HU Jinghong. Fracturing fluid backflow model and its application [D]. Chengdu: Southwest Petroleum University, 2007. 